\title{
Oncological results of surgical treatment versus organ-function preservation in larynx and hypopharynx cancer
}

\author{
Oscar Israel Jaramillo Calvas ${ }^{1}$, Daniel Marin Ramos², Leandro luongo Matos ${ }^{3 *}$, Marco Aurélio Vamondes Kulcsar ${ }^{4}$, \\ Rogério Aparecido Dedivitis ${ }^{5}$, Lenine Garcia Brandão ${ }^{6}$, Claudio Roberto Cernea ${ }^{7}$ \\ 'Resident Physician, Division of Head and Neck Surgery, Faculdade de Medicina da Universidade de São Paulo (FMUSP), São Paulo, SP, Brazi \\ ${ }^{2}$ Assistant Physician, Instituto do Câncer do Estado de São Paulo (Icesp). Division of Head and Neck Surgery, FMUSP, São Paulo, SP, Brazil \\ ${ }^{3}$ Professor, Habilitation, Division of Head and Neck Surgery, FMUSP. Assistant Physician, Icesp, São Paulo, SP, Brazil \\ ${ }^{4}$ Professor, Habilitation, Head of Outpatient Clinic at ICESP. Division of Head and Neck Surgery, FMUSP, São Paulo, SP, Brazil \\ ${ }^{5}$ Professor, Habilitation, Division of Head and Neck Surgery, and Head of the Larynx Team at Hospital das Clínicas, FMUSP, São Paulo, SP, Brazil \\ ${ }^{6}$ Full Professor, Division of Head and Neck Surgery, FMUSP, São Paulo, SP, Brazi \\ 'Professor, Head of the Division of Head and Neck Surgery, FMUSP, São Paulo, SP, Brazi
}

Study conducted at Division of Head and Neck Surgery, Faculdade de Medicina da Universidade de São Paulo (FMUSP), São Paulo, SP, Brazil

Article received: $4 / 15 / 2017$ Accepted for publication: 5/22/2017

*Correspondence: Address: Av. Dr. Enéas de Carvalho Aguiar, 255, $8^{\circ}$ andar, sala 8.174 São Paulo, SP - Brazil Postal code: 05403-000 I.matos@fm.usp.br

http://dx.doi.org/10.1590/1806-9282.63.12.1082

\section{SUMmARY}

Introduction: Since the beginning of the 1990s, non-surgical radiochemotherapy treatment has become popular with the prospect of maintaining oncological results and preserving the organ in patients with advanced squamous cell carcinoma of the larynx and hypopharynx. However, subsequent studies demonstrated increased recurrence and mortality after the non-surgical treatment became popular.

Objective: To compare the oncological results of surgical and non-surgical treatments of patients with larynx and hypopharynx cancer and to evaluate the variables associated with disease recurrence.

Method: This is a retrospective cohort study of 134 patients undergoing surgical (total or partial laryngectomy) or non-surgical (isolated radiotherapy, chemotherapy or induction chemotherapy followed by radiotherapy and chemotherapy) treatment, with 62 patients in the surgical group and 72 in the non-surgical group.

Results: Disease-free survival rates were higher in the surgical group (81.7\% vs. 62.2\%; $\mathrm{p}=0.028$ ), especially in III/IV stages ( $\mathrm{p}=0.018$ ), locally advanced tumors T3 and T4a $(\mathrm{p}=0.021)$ and $\mathrm{N} 0 / \mathrm{N} 1$ cases $(\mathrm{p}=0.005)$. The presence of cervical lymph nodes, especially $\mathrm{N} 2 / \mathrm{N} 3$, was considered a risk factor for disease recurrence in both groups $(\mathrm{HR}=11.82$; 95CI 3.42-40.88; $\mathrm{p}$ 0.0001). Patients not undergoing surgical treatment were 3.8 times more likely to develop recurrence (HR=3.76; 95CI 1.27-11.14; $\mathrm{p}=0.039)$. Conclusion: Patients with larynx or hypopharynx cancer non-surgically treated had a poorer disease-free survival, especially in cases with locally advanced tumors (T3 and T4a) and in which the neck was only slightly affected (N0/N1).

Keywords: laryngeal neoplasms, hypopharyngeal neoplasms, carcinoma, squamous cell, laryngectomy, radiotherapy, drug therapy.

\section{INTRODUCTION}

Traditionally, the treatment of squamous cell carcinoma of the larynx and hypopharynx has been performed by means of surgical resection, followed or not by adjuvant treatment, with total laryngectomy plus neck dissection being the procedure of choice in most cases. Despite its good oncological result, total laryngectomy is a treatment option that involves great impact on the patient's quality of life, mainly due to the presence of definitive tracheostoma and loss of laryngeal voice. ${ }^{1}$
Since the beginning of the 1990s, some studies on radiotherapy-based treatment ${ }^{2}$ and its association with chemotherapy ${ }^{3}$ have shown oncological results similar to those obtained with surgical treatment, with some probability of preserving the larynx. Initially, sequential chemotherapy and radiotherapy were proposed. Subsequently, the concurrent approach yielded superior results. ${ }^{4,5}$ Organ-preserving protocols based on radiochemotherapy, including new induction chemotherapy protocols, ${ }^{6}$ have become popular, whereas the open surgical approach has 
become an exception, often reserved for rescue situations when primary treatment has failed.?

In the United States, however, subsequent studies have shown a decrease in overall survival among those patients, as opposed to improved results with the treatment of other tumors, coinciding with the indication for non-surgical treatment having become more popular. ${ }^{8,9}$ In addition, anatomically preserving an organ does not necessarily mean functionally preserving it. ${ }^{10}$ Many patients undergoing non-surgical treatment show great difficulty in reassuming the laryngeal functions of phonation and airway protection.

Currently, it is accepted that, in patients with locally advanced tumors (T4a), the best oncologic result is obtained with surgical treatment, which, however, often involves complete organ resection. Nevertheless, in case of moderately advanced tumors eligible for total laryngectomy (T3 and T4a, selected), there still is controversy regarding the oncological results of organ-preserving protocols. ${ }^{11}$

Thus, our study's objective was to compare the oncological results of surgical and non-surgical treatments of patients with larynx and hypopharynx cancer and to evaluate the variables associated with disease recurrence.

\section{Method}

This is a retrospective cohort study, approved by the Institutional Ethics Committee, protocol number 228/14, including patients undergoing surgical treatment (total or partial laryngectomy) and non-surgical treatment (isolated radiotherapy, radiotherapy concurrently with chemotherapy, or induction chemotherapy followed by radiotherapy and chemotherapy) for squamous cell carcinoma of the larynx or hypopharynx, in a tertiary referral oncological hospital oncology from 2009 to 2013.

Inclusion criteria were patients with neoplasia with histopathological confirmation of squamous cell carcinoma of the larynx or hypopharynx. Patients with distant metastasis diagnosed prior to initiation of treatment, patients considered inoperable, compromised margins when undergoing surgical treatment, cases undergoing treatment without curative purposes (palliative chemotherapy or hypofractionated radiotherapy) and patients without adequate follow-up were excluded. Thus, the sample was comprised of 134 patients, of whom 62 were in the surgical group (followed or not by adjuvant radiotherapy and/or chemotherapy) and 72 in the non-surgical group, receiving different therapeutic modalities. The standardized radiotherapy dose used was 5,040 cGy on the surgical bed of the patients operated on, 7,000 cGy to the primary tumor and $6,400 \mathrm{cGy}$ for the lymphatic drainage areas, fractionated in doses of 200 cGy each, for the patients in the non-surgical group.

\section{Statistical analysis}

We describe the values we obtained from studying each quantitative variable as means and standard deviations, whereas we use absolute and relative frequencies for the qualitative variables. The distributions were defined as parametric by the Kolmogorov-Smirnov test. We used the Student's t-test to compare the means and the Chi-square test to compare the frequencies between groups of qualitative variables. The Kaplan-Meier method was used in survival analyses. The Log-rank test was used in the comparison between the curves and the Cox regression model for calculating the hazard ratio (HR) with the respective 95\% confidence interval $(95 \mathrm{CI})$ in the multivariate analysis. In all of the analyses, we employed the statistical software SPSS ${ }^{\circledR}$ version 17.0 (SPSS ${ }^{\circledR}$ Inc., Illinois, USA) and adopted a level of statistical significance below $5 \%(\mathrm{p} \leq 0.05)$ in all comparisons.

\section{Results}

The group receiving non-surgical treatment included 72 patients: 23 (31.9\%) underwent exclusive radiotherapy, 33 $(45.8 \%)$ received chemotherapy concurrently with radiotherapy and 16 (22.9\%) received induction chemotherapy followed by chemotherapy concurrently with radiotherapy; 8 patients $(24.2 \%)$ in the concurrent treatment group and 7 (43.7\%) patients who received induction did not complete all chemotherapy cycles. Of the 62 patients who received surgical treatment, $53(85.48 \%)$ underwent total laryngectomy or pharyngolaryngectomy, whereas 9 (14.51\%) underwent partial surgeries, and 38 (61.3\%) were given adjuvant treatment (22 or $35.5 \%$ received exclusive radiotherapy and 16 or $25.8 \%$ received chemotherapy concurrent with radiotherapy). The mean follow-up time in the non-surgical group was 32 months versus 29 months in the surgical group.

The two groups were similar with regard to age and gender $(\mathrm{p}=0.430$ and $\mathrm{p}=0.630$, respectively). In the surgical group, there were 50 male patients $(80.64 \%)$ with a mean age of $61.2 \pm 9.4$ years, and $59(81.94 \%)$ in the nonsurgical group, with a mean age of $62.6 \pm 10.1$ years. Considering all cases, the most common primary tumor site was the larynx (68.2\%), with no significant difference between the two groups $(\mathrm{p}=0.682)$. Most patients had advanced tumors, with $28.3 \%$ T3 and $47.1 \%$ T4a. More advanced tumors were more frequent in the surgical group $(\mathrm{p}=0.004)$. Similarly, clinical stage IV was the most prevalent in both groups (52.9\%), with the surgical group also being comprised of more patients in this stage $(\mathrm{p}=0.028)$. 
About half (50.7\%) of the patients did not have cervical metastasis at the beginning of treatment, $22.5 \%$ were classified as N2c and $13.4 \%$, as N2b. The prevalence of cervical metastasis was not significantly different between the two groups $(\mathrm{p}=0.499)$. Alcoholism and smoking reached high rates, $88.8 \%$ and $60.5 \%$ respectively, with no difference between the groups ( $\mathrm{p}=0.590$ and $\mathrm{p}=0.560$, respectively). The sampling and homogeneity data of the groups are detailed in Table 1.

Overall survival of all patients in the study was $79.2 \%$, whereas disease-free survival was $70.6 \%$, with four deaths in the surgical group versus eight in the non-surgical group $(\mathrm{p}=0.412)$. Recurrence or persistence of disease was found in 27 patients (20.1\%): seven in the surgical group $(25.9 \%$, four regional recurrences, two isolated distant recurrences, and one recurrence classified as both); whereas 20 in the non-surgical group (74.1\%; ten locoregional recurrences, six isolated distant recurrences, two local recurrences, and two concurrent recurrences - both locoregional and distant ones). In comparing disease-free survival between the two groups, we observed better results in patients who underwent laryngectomy, with $81.7 \%$ disease-free survival (seven events in 53 cases) as compared to $62.2 \%$ (20 events in 68 cases) in the non-surgical group ( $\mathrm{p}=0.028)$.

In order to explore this difference, we went on to compare disease-free survival in the different clinical stages $\mathrm{T}$ and $\mathrm{N}$ between the two groups. Initially, we compared the two anatomical sites (larynx and hypopharynx), which might represent a selection bias in our study, but we found no significant differences in diseasefree survival between the two groups $(\mathrm{p}=0.073)$. Thus, we kept the two sites grouped in the subsequent analyses.

TABLE 1 Demographic and clinical data of the sample and analysis of group homogeneity $(n=134)$.

\begin{tabular}{|c|c|c|c|c|}
\hline Variable & $\begin{array}{l}\text { Total } \\
\text { n (\%) }\end{array}$ & $\begin{array}{l}\text { Surgery } \\
\text { n (\%) }\end{array}$ & $\begin{array}{l}\text { Non-surgery } \\
\text { n (\%) }\end{array}$ & $\mathbf{p}$ \\
\hline Sex & & & & $0.630^{\#}$ \\
\hline Male & $109(81.4)$ & $50(80.6)$ & 59 (81.9) & \\
\hline Female & $25(18.6)$ & $12(19.4)$ & $13(18.1)$ & \\
\hline Age (years)* & $61.4 \pm 9.8$ & $61.2 \pm 9.4$ & $62.6 \pm 10.1$ & $0.430^{+}$ \\
\hline Comorbidities & $63(47.0)$ & $28(45.2)$ & $35(48.6)$ & $0.690^{\#}$ \\
\hline Primary site & & & & $0.682^{\#}$ \\
\hline Larynx & $90(68.2)$ & $42(70.0)$ & $48(66.7)$ & \\
\hline Hypopharynx & $42(31.8)$ & $18(30.0)$ & $24(33.3)$ & \\
\hline Cancer staging $(T)$ & & & & $0.004^{\#}$ \\
\hline T1a & $8(5.9)$ & - & $8(11.1)$ & \\
\hline T1b & $10(7.5)$ & $3(4.8)$ & $7(9.8)$ & \\
\hline $\mathrm{T} 2$ & $15(11.2)$ & $6(9.8)$ & $9(12.5)$ & \\
\hline T3 & $38(28.3)$ & $14(22.7)$ & $24(33.3)$ & \\
\hline T4a & $63(47.1)$ & $39(62.9)$ & $24(33.3)$ & \\
\hline Cancer staging $(\mathrm{N})$ & & & & $0.499^{\#}$ \\
\hline No & $68(50.7)$ & $29(46.8)$ & $39(54.2)$ & \\
\hline N1 & $13(9.7)$ & $7(11.3)$ & $6(8.2)$ & \\
\hline $\mathrm{N} 2 \mathrm{a}$ & $3(2.2)$ & $1(1.6)$ & $2(2.8)$ & \\
\hline $\mathrm{N} 2 \mathrm{~b}$ & $18(13.4)$ & $6(9.7)$ & $12(16.7)$ & \\
\hline $\mathrm{N} 2 \mathrm{c}$ & $30(22.5)$ & $18(29.0)$ & $12(16.7)$ & \\
\hline N3 & $2(1.5)$ & $1(1.6)$ & $1(1.4)$ & \\
\hline Cancer staging & & & & $0.028^{\#}$ \\
\hline 1 & $18(13.4)$ & $3(4.9)$ & $15(20.8)$ & \\
\hline II & $9(6.7)$ & $5(8.0)$ & $4(5.6)$ & \\
\hline III & $26(26.9)$ & $15(24.2)$ & $21(29.2)$ & \\
\hline IV & $71(52.9)$ & $39(62.9)$ & $32(44.4)$ & \\
\hline Smoking habit & $119(88.8)$ & $54(87.1)$ & $65(90.3)$ & $0.560^{\#}$ \\
\hline Alcohol abuse & $81(60.5)$ & $39(62.9)$ & $42(58.3)$ & $0.590^{\#}$ \\
\hline
\end{tabular}

*Mean \pm standard deviation; "Chi-square; 'Student's t-test. 
We then noted that, in stage III/IV patients, disease-free survival was higher in the surgical group (78.2\%) compared to the radiochemotherapy group $(55.5 \%, \mathrm{p}=0.018)$. Patients were classified according to stage T: the oncological outcome in terms of the therapeutic modality used in patients with early-stage disease (T1 and T2) was not significantly different (surgical and non-surgical treatment, $p=0.328$ ). Yet, we found that, in advancedstage patients (T3 and T4a), disease-free survival was higher in individuals who underwent surgical treatment $(\mathrm{p}=0.021)$. Additionally, when we compared survival between the two groups by dividing the patients according to neck staging, we found better oncological results for the surgical treatment in $\mathrm{N} 0$ or $\mathrm{N} 1$ neck cases $(\mathrm{p}=0.05)$. In $\mathrm{N} 2$ or $\mathrm{N} 3$ neck cases, in turn, there was no difference between the surgical and non-surgical groups $(\mathrm{p}=0.397)$. Comparative data for disease-free survival by different staging are shown in Table 2.

TABLE 2 Comparison of patients with squamous cell carcinoma of the larynx and hypopharynx who underwent surgical and non-surgical treatment for disease-free survival, stratified by site, staging, and T and N classification (separately and grouped).

Variables

Events/Total

Accumulated survival (\%)

P

(Log-rank)

Anatomical site

\begin{tabular}{lcc}
\hline Larynx & $12 / 82$ & 77.8 \\
\hline Hypopharynx & $15 / 39$ & 54.7 \\
\hline
\end{tabular}

Stage

Stage I/II

\begin{tabular}{lll}
\hline Surgical group & $0 / 6$ & 100. \\
\hline Non-surgical group & $1 / 18$ & 85.7 \\
\hline Stage III/IV & & 78.2 \\
\hline Surgical group & $7 / 47$ & 55.5 \\
\hline Non-surgical group & $19 / 50$ &
\end{tabular}

$\mathrm{T} 1 / \mathrm{T} 2$

\begin{tabular}{lll}
\hline Surgical group & $0 / 7$ & 100.0 \\
\hline Non-surgical group & $2 / 23$ & 85.0
\end{tabular}

T3/T4a

$7 / 46$

\begin{tabular}{lll}
\hline Surgical group & $7 / 46$ & 77.6 \\
\hline Non-surgical group & $18 / 45$ & 54.2
\end{tabular}

T4a alone

\begin{tabular}{lll}
\hline Surgical group & $6 / 34$ & 72.5 \\
\hline Non-surgical group & $11 / 23$ & $44.2^{*}$ \\
\hline
\end{tabular}

\section{$\mathrm{N}$ Classification}

N0 alone

\begin{tabular}{|c|c|c|c|}
\hline Surgical group & $0 / 25$ & 100.0 & \\
\hline Non-surgical group & $6 / 38$ & 76.4 & \\
\hline N1 alone & & & 0.029 \\
\hline Surgical group & $0 / 4$ & 100.0 & \\
\hline Non-surgical group & $4 / 6$ & $20.8^{* *}$ & \\
\hline No/N1 & & & 0.005 \\
\hline Surgical group & $0 / 29$ & 100.0 & \\
\hline Non-surgical group & $10 / 44$ & 68.7 & \\
\hline $\mathrm{N} 2 / \mathrm{N} 3$ & & & 0.397 \\
\hline Surgical group & $7 / 24$ & 59.6 & \\
\hline Non-surgical group & $10 / 24$ & 51.2 & \\
\hline
\end{tabular}


TABLE 2 (Cont.) Comparison of patients with squamous cell carcinoma of the larynx and hypopharynx who underwent surgical and non-surgical treatment for disease-free survival, stratified by site, staging, and $\mathrm{T}$ and $\mathrm{N}$ classification (separately and grouped)

Variables

Events/Total

Accumulated survival (\%)

P

(Log-rank)

Grouped $\mathrm{T}$ and $\mathrm{N}$ classification

T3 N0

$\begin{array}{lll}\text { Surgical group } & 0 / 6 & 100.0 \\ \text { Non-surgical group } & 3 / 15 & 75.5\end{array}$

T4a NO

Surgical group $\quad 0 / 13 \quad 100.0$

Non-surgical group $\quad 2 / 5$

\begin{tabular}{lll} 
T3/T4a N0 & \\
\hline Surgical group & $0 / 19$ & 100.0 \\
\hline Non-surgical group & $5 / 20$ & 70.0
\end{tabular}

$\mathrm{T} 3 \mathrm{NO} / \mathrm{N}$

Surgical group $\quad 0 / 8 \quad 100.0$

Non-surgical group $\quad 4 / 17 \quad 72.1$

$\begin{array}{ll}\text { T4a N0/N1 } & 0.001\end{array}$

\begin{tabular}{lll}
\hline Surgical group & $6 / 34$ & 72.5 \\
\hline Non-surgical group & $5 / 8$ & $29.2 * *$
\end{tabular}

T3/T4a N0/N1 0004

$\begin{array}{lll}\text { Surgical group } & 0 / 23 & 100.0\end{array}$

Non-surgical group $\quad 9 / 25$

* Median survival attained in 10 months.

**Median survival attained in 2 months.

When we compared the accumulated disease-free survival, grouping advanced T-stages and early $\mathrm{N}$-stages (these patients had the best results with the surgical treatment; Table 2), we also observed better results in the surgical group, especially in the cases involving tumors $\mathrm{T} 4 \mathrm{a}$ (T4aN0, $\mathrm{p}=0.036$; and T4aN1, $\mathrm{p}=0.001$ ).

In the multivariate analysis (Table 3), we found that the non-surgical treatment and the presence of $\mathrm{N}$ positive, especially $\mathrm{N} 2 / \mathrm{N} 3$ nodal disease, were independent risk factors for disease progression $(\mathrm{HR}=3.76, \mathrm{p}=0.017$; and $\mathrm{HR}=11.82, \mathrm{p}<0.0001$, respectively). Furthermore, smoking was a factor associated with better progression, with lower persistence and disease recurrence rates $(\mathrm{HR}=0.08$; $\mathrm{p}<0.0001)$. Once again, we found that the anatomic site, larynx or hypopharynx, was not an independent risk variable in this analysis $(\mathrm{HR}=1.31, \mathrm{p}=0.589)$.

\section{Discussion}

Over the last few decades, there has been a shift in the treatment strategy for larynx cancer with advanced locoregional disease. There was an increase in the number of patients undergoing radiotherapy and chemotherapy and a decrease in the number of those treated with surgery. ${ }^{5,10,11}$ According to the guidelines of the American Society of Clinical Oncology, disease management in association with larynx preservation was considered appropriate for most patients with $\mathrm{T} 3$ and $\mathrm{T} 4$ tumors without invasion into soft tissues through the cartilage. ${ }^{12}$

In our study, we found greater disease-free survival in patients with larynx or hypopharynx squamous cell carcinoma who were initially treated with surgery compared to those included in organ-preserving protocols. A multivariate analysis further corroborated this finding, in spite of the surgical group including patients with more advanced tumors. This clearly differs from some studies advocating conservative treatment in cases of advanced carcinomas of the larynx and hypopharynx. ${ }^{2-6}$

This difference was better characterized when contrasting the groups across the different $\mathrm{T}$ and $\mathrm{N}$ classifications. At this point, better oncological results were observed in patients with T3 and T4a tumors (mainly T4a) undergoing surgical treatment, which is partly in agreement with the literature. ${ }^{10,13,14}$ Currently, what appears to be most generally accepted is that T4a tumors 
TABLE 3 Multivariate analysis of risk related to disease relapse/persistence.

\begin{tabular}{|c|c|c|c|}
\hline Variables & HR & $95 \mathrm{Cl}$ & $\mathrm{p}^{*}$ \\
\hline Age & 0.99 & $0.95-1.03$ & 0.599 \\
\hline \multicolumn{4}{|c|}{ Treatment modality } \\
\hline Surgery & Reference & & \\
\hline Non-surgery & 3.76 & $1.27-11.14$ & 0.017 \\
\hline \multicolumn{4}{|l|}{ Anatomical site } \\
\hline Larynx & Reference & & \\
\hline Hypopharynx & 1.31 & $0.49-3.53$ & 0.589 \\
\hline \multicolumn{4}{|c|}{ Presence of comorbidity } \\
\hline No & Reference & & \\
\hline Yes & 0.80 & $0.34-1.90$ & 0.612 \\
\hline \multicolumn{4}{|c|}{ Cancer staging $(\mathrm{T})$} \\
\hline $\mathrm{T} 1 / \mathrm{T} 2$ & Reference & & \\
\hline T3/T4a & 2.89 & $0.62-13.61$ & 0.178 \\
\hline \multicolumn{4}{|c|}{ Cancer staging $(\mathrm{N})$} \\
\hline No & Reference & & \\
\hline $\mathrm{N}+$ & 6.49 & $2.17-19.37$ & 0.001 \\
\hline N0/N11 & Reference & & \\
\hline $\mathrm{N} 2 / \mathrm{N} 3$ & 11.82 & $3.42-40.88$ & $<0.0001$ \\
\hline \multicolumn{4}{|l|}{ Cancer staging } \\
\hline $1 / 11$ & Reference & & \\
\hline III/IV & 2.05 & $0.10-41.67$ & 0.640 \\
\hline \multicolumn{4}{|l|}{ Smoking habit } \\
\hline No & Reference & & \\
\hline Yes & 0.07 & $0.02-0.22$ & $<0.0001$ \\
\hline \multicolumn{4}{|l|}{ Alcohol abuse } \\
\hline No & Reference & & \\
\hline Yes & 1.23 & $0.32-4.73$ & 0.767 \\
\hline
\end{tabular}

(with coarse cartilage invasion and laryngeal extravasation) should be preferentially treated with surgery. Nevertheless, for T3 tumors, a course of conduct has not been well established yet. ${ }^{15}$ Our study shows a trend towards better outcomes with surgery on intermediate tumors, which certainly encourages further studies.

As for lymph node status, when we stratified neck staging, we observed disease-free survival only in N0 and N1 cases, with better results in the surgical group as well. This was probably due to a worse prognosis inherent in the regional disease, diluting any benefit the surgical treatment could bring. In our study, the presence of cervical metastasis impacted on the decrease in disease-free survival also in the multivariate analysis.

Our main finding is the identification of laryngectomy as the best therapeutic modality for advanced tumors of the larynx and hypopharynx. In a first analysis, it may seem strange to group the two distinct sites in a joint analysis. Still, when dealing specifically with patients who have advanced disease with these topographies, it is not always possible to determine the epicenter of the tumor due to its bulky dimensions and/or involvement of multiple contiguous subsites. Furthermore, both the univariate and multivariate analyses showed, respectively, that the anatomical site (larynx or hypopharynx) was neither an associated nor a predictive variable with respect to the risk of recurrence or persistence of disease in these patients. Thus, we chose to keep the total sample in the subsequent analyses.

One of the limitations of the study is the relative heterogeneity of the groups because it is a historical cohort and not a randomized study. The surgical arm groups together patients who underwent total laryngectomy, pharyngolaryngectomy or partial laryngectomy, with or 
without dissection, and with an adjuvant in some cases. The non-surgical arm, on the other hand, gathers exclusive radiotherapy, concurrent radiotherapy and chemotherapy, some cases of induction chemotherapy followed by radiotherapy and chemotherapy, and patients who did not complete the three cycles of concurrent chemotherapy. There are many different therapeutic modalities being compared, which makes it difficult to define the real benefit deriving from each one. Similarly, there is the inherent information bias of retrospective studies, which is in fact difficult to discriminate statistically. The selection of patients for each of the therapeutic arms may also be debated. However, it was mostly done at random as external referral of patients to our health care service. Still, the study has invaluably contributed to answering an essential question: is the current indiscriminate indication of organ-preserving protocols a sound practice in cases of moderately advanced larynx or hypopharynx tumor? The answer is no. It is essential that these patients be evaluated by a head and neck surgeon in an attempt to perform precise staging and provide an adequate definition of the treatment to be used multidisciplinarily. Certainly, further studies are required to define the exact cut-off point from which it is no longer possible or safe to attempt non-surgical treatment. Our study contributes to that end accordingly.

Based on three prospective studies that assessed 170 patients with advanced and resectable larynx or pharynx tumors, we evaluated the criteria for better indicating organpreserving protocols. We created the acronym TALK (in Portuguese), according to which patients with advanced primary tumors (T4), low albumin level $(<4 \mathrm{~g} / \mathrm{dL})$, consumption of greater quantities of alcoholic beverages $(>6$ doses/ day - letter "L" for liquor) and lower Karnofsky indexes $(<80 \%)$ were the worst success results in preserving the larynx. ${ }^{16}$

In a multicenter retrospective study with 176 patients with larynx cancer, 65 were in clinical stage III, 51 underwent organ-preserving protocols, and 14 underwent laryngectomy. Of the 111 patients in clinical stage IV, 42 were given non-surgical treatment and 69 underwent total laryngectomy. Overall and disease-specific survivals at three years were $58 \%$ and $73 \%$, respectively, for stage III and $42 \%$ and $53 \%$, for stage IV. The choice of treatment did not appear to significantly influence survival for stages III $(\mathrm{p}=0.56)$ and IV $(\mathrm{p}=0.93)$. However, there was a trend towards better outcomes with surgical treatment, especially in patients with advanced disease. ${ }^{17}$

Interestingly, our results indicate that patients with a history of smoking had better oncological results in terms of disease-free survival compared to patients with- out such a history, irrespective of treatment modality. One hypothesis for this is patients that have larynx or hypopharynx cancer, even though they are non-smokers, must have other factors directly influencing their prognosis (immunosuppression, genetic predisposition and so on). Further in-depth studies are needed to evaluate this finding.

The impact of the treatment modality, particularly for advanced stage patients (stages III and IV), was studied by Bussu et al. ${ }^{18}$ They retrospectively evaluated 166 patients with squamous cell carcinoma of the larynx treated with total laryngectomy, partial supracricoid laryngectomy or a combination of radiotherapy and chemotherapy. The organ preservation rate was $45 \%$ in the clinical group versus $76.7 \%$ for partial laryngectomy $(\mathrm{p}=0.0002)$. In T4a cases, they found improved survival in patients treated with total laryngectomy $(78 \%$ vs. $68 \%$ for partial laryngectomy, and 54\% for the combination of radiotherapy and chemotherapy at three years, $\mathrm{p}=0.031$ ). These data corroborate the findings of our study for this group of patients.

No other non-surgical treatment has greater survival than the initial radical surgery. ${ }^{1}$ Accordingly, our results are in agreement with what most studies in the literature show, which corroborates the thesis that the best treatment for moderately advanced and advanced tumors (T3 and T4a) is surgery followed or not by an adjuvant treatment for increased disease-free survival.

\section{Conclusion}

Patients non-surgically treated had poorer disease-free survival. Additionally, the presence of lymph node metastases was an independent risk factor for recurrence in both groups. Smoking was a factor associated with lower disease recurrence, irrespective of the treatment used.

\section{Conflict of interest}

The authors declare no conflict of interest.

\section{Resumo}

Resultado oncológico de tratamento cirúrgico versus protocolo de preservação de órgão em câncer de laringe e hipofaringe

Introdução: A partir de estudos do início dos anos 1990, popularizou-se o tratamento não cirúrgico com radioquimioterapia, com a perspectiva de manutenção do resultado oncológico e preservação do órgão em pacientes com carcinoma espinocelular avançado de laringe e hi- 
pofaringe. Entretanto, estudos posteriores demonstraram aumento da recorrência e da mortalidade com a difusão do tratamento não cirúrgico.

Objetivo: Comparar o resultado oncológico dos tratamentos cirúrgico e não cirúrgico de pacientes com câncer de laringe e hipofaringe e avaliar as variáveis associadas à recidiva de doença.

Método: Estudo de coorte retrospectiva de pacientes submetidos ao tratamento cirúrgico (laringectomia total ou parcial) e não cirúrgico (radioterapia isolada, radioterapia concomitante a quimioterapia ou quimioterapia de indução seguida de radioterapia e quimioterapia) de 134 pacientes, sendo 62 no grupo cirúrgico e 72 no não cirúrgico. Resultados: As taxas de sobrevivência livre de doença foram maiores no grupo cirúrgico $(81,7 \%$ vs. $62,2 \% ; \mathrm{p}=0,028)$, principalmente em estádios III/IV ( $\mathrm{p}=0,018)$, tumores localmente avançados T3 e T4a $(\mathrm{p}=0,021)$ e casos N0/N1 $(\mathrm{p}=0,005)$. A presença de linfonodos cervicais, principalmente $\mathrm{N} 2 / \mathrm{N} 3$, foi considerada fator de risco para recidiva de doença nos dois grupos (HR=11,82; IC95\% 3,42-40,88; $\mathrm{p}<0,0001)$. Pacientes não submetidos ao tratamento cirúrgico apresentaram 3,8 vezes mais chance de desenvolvimento de recidiva ( $\mathrm{HR}=3,76$; IC95\% 1,27-11,14; $\mathrm{p}=0,017)$. Conclusão: Pacientes com câncer de laringe ou hipofaringe tratados de forma não cirúrgica tiveram menor sobrevivência livre de doença, especialmente nos tumores localmente avançados (T3 e T4a) e com pescoço pouco comprometido (N0/N1).

Palavras-chave: neoplasias laríngeas, neoplasias hipofaríngeas, carcinoma de células escamosas, laringectomia, radioterapia, tratamento farmacológico.

\section{References}

1. Olsen KD. Reexamining the treatment of advanced laryngeal cancer. Head Neck. 2010; 32(1):1-7.

2. Department of Veterans Affairs Laryngeal Cancer Study Group, Wolf GT, Fisher SG, Hong WK, Hillman R, Spaulding M, Laramore GE, et al. Induction chemotherapy plus radiation compared with surgery plus radiation in patients with advanced laryngeal cancer. N Engl J Med. 1991; 324(24):1685-90.

3. MacKenzie RG, Franssen E, Balogh JM, Gilbert RW, Birt D, Davidson J Comparing treatment outcomes of radiotherapy and surgery in locally advanced carcinoma of the larynx: a comparison limited to patients eligible for surgery. Int J Radiat Oncol Biol Phys. 2000; 47(1):65-71.

4. Forastiere AA, Goepfert H, Maor M, Pajak TF, Weber R, Morrison W, et al. Concurrent chemotherapy and radiotherapy for organ preservation in advanced laryngeal cancer. N Engl J Med. 2003; 349(22):2091-8.

5. Forastiere AA, Zhang Q, Weber RS, Maor MH, Goepfert H, Pajak TF, et al. Long-term results of RTOG 91-11: a comparison of three nonsurgical treatment strategies to preserve the larynx in patients with locally advanced larynx cancer. J Clin Oncol. 2013; 31(7):845-52.

6. Pfiser DG, Ridge JA. Induction chemotherapy for larynx preservation: patient selection or therapeutic effect? J Clin Oncol. 2006; 24(4):540-3.

7. Stanković M, Milisavljević D, Stojanov D, Zivić M, Zivaljević S, Stanković I, et al. Influential factors, complications and survival rate of primary and salvage total laryngectomy for advanced laryngeal cancer. Coll Antropol. 2012; 36(Suppl 2):7-12.

8. Carvalho AL, Nishimoto IN, Califano JA, Kowalski LP. Trends in incidence and prognosis for head and neck cancer in the United States: a site-specific analysis of the SEER database. Int J Cancer. 2005; 114(5):806-16.

9. Hoffman HT, Porter K, Karnell LH, Cooper JS, Weber RS, Langer CJ, et al. Laryngeal cancer in the United States: changes in demographics, patterns of care, and survival. Laryngoscope. 2006; 116(9 Pt 2 Suppl 111):1-13.

10. Lefebvre JL. Candidates for larynx preservation: the next step? Oncologist. 2010; 15(Suppl 3):30-2.

11. Silver CE, Beitler JJ, Shaha AR, Rinaldo A, Ferlito A. Current trends in initial management of laryngeal cancer: the declining use of open surgery. Eur Arch Otorhinolaryngol. 2009; 266(9):1333-52.

12. American Society of Clinical Oncology, Pfister DG, Laurie SA, Weinstein GS, Mendenhall WM, Adelstein DJ, Ang KK, et al. American Society of Clinical Oncology clinical practice guideline for the use of larynx-preservation strategies in the treatment of laryngeal cancer. J Clin Oncol. 2006; 24(22):3693-704.

13. Lefebvre JL, Ang KK; Larynx Preservation Consensus Panel. Larynx preservation clinical trial design: key issues and recommendations: a consensus panel summary. Int J Radiat Oncol Biol Phys. 2009; 73(5):1293-303.

14. Chen AY, Halpern M. Factors predictive of survival in advanced laryngeal cancer. Arch Otolaryngol Head Neck Surg. 2007; 133(12):1270-6.

15. Agra IM, Ferlito A, Takes RP, Silver CE, Olsen KD, Stoeckli SJ, et al. Diagnosis and treatment of recurrent laryngeal cancer following initial nonsurgical therapy. Head Neck. 2012; 34(5):727-35.

16. Sherman EJ, Fisher SG, Kraus DH, Zelefsky MJ, Seshan VE, Singh B, et al. TALK Score: development and validation of a prognostic model for predicting larynx preservation outcome. Laryngoscope. 2012; 122(5):1043-50.

17. Karlsson TR, Al-Azzawe M, Aziz L, Hurman D, Finizia C. Survival outcome depending on different treatment strategies in advanced stages III and IV laryngeal cancers: an audit of data from two European centres. Eur Arch Otorhinolaryngol. 2014; 271(3):547-54.

18. Bussu F, Paludetti G, Almadori G, De Virgilio A, Galli J, Miccichè F, et al Comparison of total laryngectomy with surgical (cricohyoidopexy) and nonsurgical organ-preservation modalities in advanced laryngeal squamous cell carcinomas: a multicenter retrospective analysis. Head Neck. 2013; 35(4):554-61. 